\title{
Extremely Dense Breast
}

National Cancer Institute

\section{Source}

National Cancer Institute. Extremely Dense Breast. NCI Thesaurus. Code C132104.

A mammographic finding of extremely dense breast composition, as defined by the visually estimated content of fibroglandular-density tissue within the breast, based on updated editions of the American College of Radiology's Breast Imaging Reporting and Data System (BI-RADS). 